\title{
Coro Dona Góspel: un camino musical hacia lo mejor de sí mismas. Diagnóstico participativo en el colectivo de mujeres en prostitución ${ }^{1}$
}

\author{
Constanza Victoria Espinoza Jiménez ${ }^{2}$
}

\begin{abstract}
El presente estudio busca comprender el papel de la música como herramienta de inclusión social en un colectivo de mujeres inmigrantes que ejercen la prostitución en la ciudad de Barcelona, España. Desde una mirada sociocrítica y utilizando la metodología de diagnóstico participativo con enfoque etnográfico, participamos activamente en ensayos y conciertos de un coro llamado Dona Góspel para recoger evidencias sobre los beneficios, tanto individuales como colectivos, que brinda el desarrollo de una actividad musical en conjunto.
\end{abstract}

Palabras clave: prostitución, inclusión social, música, diagnóstico participativo

\section{Dona Gospel Choir: a musical journey towards their best version, a participatory diagnostic study of a group of women in prostitution}

\section{ABSTRACT}

The present study aims to understand the role of music as a tool for social inclusion in a group of immigrant women working as prostitutes. From a socio-critical perspective and using the participatory diagnostic methodology with an ethnographic approach, we actively participate in rehearsals and concerts of the Dona Gospel choir to collect evidence on their individual and collective benefits from the development of a group musical activity.

Keywords: prostitution, social inclusion, music, participatory diagnostic

Artículo recibido el 16/09/2018. Artículo Aceptado el 16/12/2018.

Chilena, Profesora de Música. Universidad Católica Silva Henríquez. E-mail: cespinoza@ucsh.cl 


\section{Coro Dona Góspel: um caminho musical rumo ao melhor de si mesmas. Diagnóstico participativo no coletivo de mulheres em prostituição}

\section{RESUMO}

O presente estudo busca assinalar o papel da música como ferramenta de inclusão social em um coletivo de mulheres imigrantes que exercem a prostituição na cidade de Barcelona. Desde um olhar sociocrítico e utilizando a metodologia de diagnóstico participativo com foco etnográfico, participamos ativamente em ensaios e concertos de um coro chamado de Dona Góspel, para recolher evidências sobre os benefícios tanto individuais quanto coletivos que oferece o desenvolvimento de uma atividade musical em conjunto.

Palavras-chave: prostituição, inclusão social, música, diagnóstico participativo

\section{Introducción}

La presente comunicación pretende comprender el alcance de la música como herramienta de inclusión social en el colectivo de mujeres inmigrantes en contextos de prostitución. El estudio se realizó en España, ciudad de Barcelona, en la entidad no gubernamental El Lloc de la Dona ${ }^{3}$ entre los años 2017 y $2018^{4}$. La entidad antes mencionada pertenece a la Congregación de las Hermanas Oblatas y, sin fines de lucro, atiende a mujeres que ejercen la prostitución y/o han sido víctimas de trata con el objetivo de mejorar su calidad de vida y sensibilizar a la ciudadanía sobre la realidad de las mujeres en prostitución (El Lloc de la Dona, 2016).

Las usuarias que ingresan a la entidad presentan necesidades en dos niveles, el primero corresponde a las necesidades básicas relacionadas con la formación en idiomas, atención sociosanitaria, extranjería, infancia y adolescencia, vivienda, entre otras. Mientras que, en un segundo nivel, las necesidades son de orden vital y guardan relación con su autoestima, hábitos y normas, y víncu-

3 En castellano: El Lugar de la Mujer. Para obtener mayor información sobre la entidad, recomendamos visitar http://www.llocdeladona.org/es/

4 Creemos necesario aclarar que, en España, el año académico comienza en septiembre de 2017 y finaliza en junio de 2018. 
los sociales con la comunidad. Para dar solución a estas necesidades, la entidad ha estructurado un itinerario formativo en tres bloques: el primero corresponde a la formación en lengua castellana, ya que muchas de ellas son africanas y no hablan dicho idioma, el segundo pretende desarrollar habilidades prelaborales para facilitar su entrada al mercado laboral, y el tercero promueve actividades de ocio con la intención de reforzar aspectos de la autoestima y establecer vínculos con la comunidad. Dentro de las actividades de ocio encontramos al Coro Dona Góspel, un taller de música vocal que lleva dos años en funcionamiento y que hemos seguido intensamente con el objetivo de comprender, analizar y sistematizar los elementos pedagógicos relevantes que evidencian el papel de la música como herramienta de inclusión.

Desde una mirada sociocrítica orientada a la acción, utilizamos la metodología de diagnóstico participativo con enfoque etnográfico, con la voluntad de sumergirnos en el escenario y rescatar y visibilizar las voces de las implicadas. Participamos durante un año en todos los ensayos y conciertos del Coro Dona Góspel para conocer la realidad pedagógica entre mujeres y educadoras, establecer mejoras e innovaciones adecuadas al coro y analizar los beneficios que la música generaba en las mujeres. El estudio se materializó en tres grandes fases: Fase I de Diagnóstico y observación participante, en la que hicimos el trabajo de campo siguiendo al coro y otras actividades formativas de la entidad; Fase II de Diseño e implementación de una intervención socioeducativa, en la que desarrollamos tres sesiones sobre música y valores, y Fase III de Análisis cualitativo de datos, en la que triangulamos la información obtenida y analizamos los resultados de la investigación.

Finalmente, pudimos ver que el Coro Dona Góspel jugó un papel relevante en los procesos de inclusión de las mujeres en prostitución, ya que se presentó como un espacio de participación ciudadana en el que las mujeres tomaron el protagonismo y fueron reconocidas como artistas por la comunidad de acogida. 


\section{Migración y comercio sexual: ¿por qué las mujeres se acercan a la prostitución?}

La inestabilidad política y económica en los países de África, Asia y América Latina, la precarización y flexibilización del empleo, y la profundización de las desigualdades (Sassen, 2003) han provocado el aumento significativo de la pobreza femenina. En este contexto, la migración hacia países desarrollados y el trabajo informal e ilegal se presentan como alternativas para la subsistencia.

Con respecto a la inmigración en España, el informe realizado por el Ministerio de Sanidad y Servicios Sociales (2015) menciona que la población femenina migrante proviene generalmente de América Latina y del continente africano. En el caso de África, la mayoría de los países subsaharianos se encuentran con los índices de desarrollo más bajos del mundo ${ }^{5}$ (PNUD, 2014) escenario propicio para que mujeres y cada vez más niñas sean el nuevo recurso mercantil en el negocio internacional de la prostitución.

En relación con las mujeres que ejercen el comercio sexual, las formas de llegada a España son variadas: desde migración individual, con pareja, mediante cadenas migratorias comunitarias -vínculos familiares y/o de amistad-, hasta estructuras más complejas, como las redes de tráfico de personas (Holgado, 2001). Al mismo tiempo, pueden ser mujeres que ya ejercían la prostitución en sus países de origen o han decidido ejercerla durante su estadía en el nuevo país. Esta realidad ha dado paso al fenómeno de sustitución en los países de acogida, en el que las mujeres extranjeras asumen los trabajos que las autóctonas ya no desean realizar. Según el Boletín Oficial de Cortes Generales (2007), el 90\% del total de mujeres que ejercen la prostitución en España son extranjeras. Si la migración y la prostitución presentan un vínculo complejo de abordar, veamos ahora cómo la prostitución puede ser observada desde múltiples aristas.

Entre estos países destaca Nigeria, último país en el Índice de Desarrollo Humano de 2014 , con una esperanza de vida de 50 años y con el 73,5\% de la población sumergida en la pobreza extrema. 


\section{La prostitución: una realidad con múltiples aristas}

En España la prostitución no está regulada ni penalizada, no obstante, lo está recientemente la trata de personas con fines de explotación sexual (Juliano, 2009). Por tanto, desde una perspectiva legal en relación con la prostitución, se han adoptado medidas prohibicionistas multando a los clientes con la consigna de que sin demanda no existe oferta (Holgado, 2001). A su vez, desde una mirada económica, la prostitución se vincula con el crecimiento de la industria del turismo y entretenimiento (Sassen, 2003), y, a pesar de no haber una legislación al respecto, dueños de clubes, personal de seguridad y contadores (entre otros) obtienen beneficios económicos del trabajo sexual que, generalmente, se lleva a cabo en los circuitos de la economía sumergida.

Al mismo tiempo, en relación con el debate feminista, existen dos posiciones predominantes (Heim, 2011). La primera es el feminismo abolicionista, en el que se considera a la prostitución como una forma de violencia hacia la mujer (Ordoñez, 2006), mientras que la segunda corresponde al feminismo pro derecho, en el que se reconoce al trabajo sexual como una opción voluntaria para obtener ingresos económicos. No obstante, ambas posturas presentan limitaciones, ya que la primera trae consigo la invisibilización de las prostitutas y la segunda deja a las trabajadoras sexuales que reivindican sus derechos expuestas al estigma social. Por ello, en esta comunicación pretendemos avanzar hacia una tercera vía, considerando a las mujeres como ciudadanas activas dentro de la comunidad a través del reconocimiento de sus saberes y talentos (Martín, Puig \& Gijón, 2018).

Por otra parte, el tratamiento más característico que se le ha dado a la prostitución ha sido la perspectiva sociosanitaria. Se han implementado planes gubernamentales para ofrecer una atención integral a las mujeres, promoviendo hábitos de vida saludable y fomentando la prevención de enfermedades, incrementando su accesibilidad a la atención sanitaria mediante el desarrollo de estrategias de captación, seguimiento de la asistencia y participación en los programas de salud pública (Cabrerizo, 2016). 
Como hemos visto, la prostitución es una realidad poliédrica (Gijón, 2012) y, por tanto, son múltiples los escenarios que viven las mujeres en este contexto. Por esta razón, desde una mirada pedagógica -enfoque que no ha sido considerado por la investigación tradicional- consideramos que la cultura y el arte pueden ser una valiosa herramienta de intervención para promover la emancipación de las mujeres en prostitución.

\section{Música e inclusión: el arte para la emancipación}

Desarrollar actividades artísticas en grupo puede traer beneficios para la reconstrucción individual y social de las personas. Veremos que, cuando la música es utilizada como una herramienta de intervención, permite desarrollar habilidades sociales y cognitivas, y promover espacios de participación ciudadana en personas que han sufrido procesos de desconexión de su comunidad. A continuación presentamos algunas experiencias que muestran cómo la música puede ir más allá de su carácter meramente instrumental, para ir al servicio de la inclusión social mediante la intervención socioeducativa.

El estudio cualitativo llamado "Bars behind bars" (Silber, 2005), realizado en un recinto penitenciario de Israel, en el que se conformó un coro de mujeres, reveló que la música potenciaba la interacción, dedicación, el compromiso y la comunicación entre las integrantes del coro y su directora. Esto les permitió desarrollar sus habilidades sociales y configurar una comunidad alternativa, sana y afectiva en un entorno de reclusión.

A la par, en el contexto latinoamericano la, "Fundación Batuta" en Colombia ha visto que el ejercicio de la música suscita una mentalidad constructiva y creativa en los/las estudiantes que se encuentran en contextos de exclusión (Sanpietro, 2015). Mientras que, en Chile, desde la esfera de la educación pública, encontramos al Liceo Artístico Guillermo G., recinto educativo que recibe a estudiantes vulnerables, donde se realizan actividades artístico-culturales de gran relevancia, con la voluntad de recuperar la calidad de la educación a través del arte (Urrutia, 2015). 
Por otra parte, y con dos años de funcionamiento, el Taller de Músics, ubicado en Barcelona, ha implementado, mediante su área de proyectos sociales, el programa "Taller Obert" para hacer llegar la práctica y la cultura musical a los colectivos en contextos de exclusión. Mientras que la institución "Apropa Cultura", con diez años de antigüedad en la misma ciudad, brinda formaciones artísticas para los y las educadores/as sociales, y ofrece entradas a precio reducido para los colectivos vulnerables. Ambas instituciones tienen un compromiso con el acceso universal a la cultura, para fomentar la participación ciudadana y garantizar la dignidad de las personas.

Como hemos visto, "el arte constituye un espacio de expresión y desarrollo personal, encuentro, participación social" (Equipo del Observatorio del Tercer Sector de Bizkaia, 2012, p. 6). Por ello, consideramos que la música puede transformarse en una experiencia emancipadora, integradora y relacional, mediante actividades que generen un goce artístico en el que no hay aciertos ni errores, causando grandes beneficios, tanto individuales como colectivos, en las personas más desfavorecidas. A continuación, veremos cómo el Coro Dona Góspel se ha convertido en un lugar de participación y disfrute para las mujeres inmigrantes que ejercen la prostitución.

\section{Metodología}

El estudio se realizó desde un enfoque sociocrítico "que se caracteriza por la constante interacción entre acción y reflexión con el objetivo puesto en la aplicación de los conocimientos para transformar la realidad" (Sabariego, 2009, p. 76). Utilizamos la metodología de Diagnóstico Participativo (DP) de corte etnográfico para comprender el papel de la música como herramienta de inclusión en el colectivo de mujeres en prostitución. El DP nos permitió indagar y conocer la realidad educativa de las mujeres en su propio contexto, con la intención de construir propuestas integrales y adecuadas a las necesidades del grupo (Folgueiras y Sabariego, 2017). Sistematizamos los datos relevantes para la comprensión del tema e identificamos recursos, potencialidades y pautas para la mejora e innovación del Coro Dona Góspel. A su vez, robustecimos nuestra 
investigación con un enfoque etnográfico, que nos permitió explorar el escenario para conocer los significados y opiniones (Sandín, 2003; Díaz de Rada y Velasco, 1997) de las usuarias y educadoras respecto del taller vocal.

\section{Escenario y participantes}

Las participantes del estudio fueron siete mujeres nigerianas que ejercen o han ejercido la prostitución y que asisten regularmente a los ensayos y conciertos del Coro Dona Góspel. Al mismo tiempo, cursan el itinerario formativo de la entidad, hablan inglés, tienen un nivel básico de castellano y sus edades fluctúan entre los 19 y 40 años. Simultáneamente, participaron su educadora referente, la educadora social que dirige el coro y la directora de Apropa Cultura. Realizamos tres entrevistas en profundidad, un grupo de discusión con las mujeres del coro y un año de trabajo de campo acompañando al Coro Dona Góspel en todos sus ensayos y conciertos.

\section{Fases metodológicas}

En la Fase I de Diagnóstico y observación participante, conocimos el contexto vital de las mujeres en prostitución e indagamos en la realidad pedagógica entre profesionales y mujeres del Coro Dona Góspel. Las técnicas de recolección utilizadas fueron: el análisis documental, tres entrevistas en profundidad, un grupo de discusión y la observación participante que fue sistematizada mediante un diario de campo.

En la Fase II de Diseño e implementación de una intervención socioeducativa (IS), planificamos e implementamos tres sesiones sobre música y valores. Sin embargo, no es objeto de esta comunicación profundizar en su desarrollo.

Finalmente, en la Fase III de Análisis cualitativo de datos, realizamos la triangulación de la información obtenida. La técnica utilizada fue el análisis cualitativo de datos sin soporte informático y se concretó en tres etapas: a) relectura, selección y codificación del material; b) triangulación y categorización de los datos; y c) 
interpretación de los resultados. En la siguiente tabla detallamos las técnicas y descripción del procedimiento realizado en la Fase I y III de la investigación.

Tabla 1: Fases y técnicas de recolección de datos

\begin{tabular}{|c|c|c|c|}
\hline $\begin{array}{c}\text { Fases de la } \\
\text { investigación }\end{array}$ & $\begin{array}{l}\text { Técnicas de } \\
\text { recolección }\end{array}$ & $\begin{array}{l}\text { Descripción del } \\
\text { procedimiento }\end{array}$ & Código \\
\hline \multirow[t]{4}{*}{$\begin{array}{l}\text { Fase I de } \\
\text { Diagnóstico y } \\
\text { observación } \\
\text { participante }\end{array}$} & $\begin{array}{l}\text { Análisis docu- } \\
\text { mental }\end{array}$ & $\begin{array}{l}\text { De la bibliografía disponible } \\
\text { sobre prostitución, migración } \\
\text { y educación artística en colec- } \\
\text { tivos vulnerables. }\end{array}$ & \\
\hline & $\begin{array}{l}\text { Observación } \\
\text { Participante }\end{array}$ & $\begin{array}{l}\text { En todas las actividades del } \\
\text { coro. El resultado de este re- } \\
\text { gistro fue la elaboración de un } \\
\text { diario de campo que contie- } \\
\text { ne información de todos los } \\
\text { ensayos y conciertos del Coro } \\
\text { Dona Góspel durante un año } \\
\text { académico. }\end{array}$ & DC_1 \\
\hline & $\begin{array}{l}\text { Entrevista en } \\
\text { profundidad }\end{array}$ & $\begin{array}{l}\text { Dirigida a la educadora refe- } \\
\text { rente de la entidad. } \\
\text { Dirigida a la directora del Co- } \\
\text { ro Dona Góspel. } \\
\text { Dirigida a la directora de } \\
\text { Apropa Cultura. }\end{array}$ & $\begin{array}{l}\text { Edu_M1 } \\
\text { Edu_N2 } \\
\text { Edu_S3 }\end{array}$ \\
\hline & $\begin{array}{l}\text { Grupo de dis- } \\
\text { cusión. }\end{array}$ & $\begin{array}{l}\text { Aplicada a siete usuarias de la } \\
\text { entidad que participaron regu- } \\
\text { larmente en ensayos y concier- } \\
\text { tos del Coro Dona Góspel }\end{array}$ & GD_Muj \\
\hline \multirow[t]{3}{*}{$\begin{array}{l}\text { Fase III de } \\
\text { Análisis cuali- } \\
\text { tativo de datos. }\end{array}$} & $\begin{array}{l}\text { Relectura, se- } \\
\text { lección y codi- } \\
\text { ficación. }\end{array}$ & $\begin{array}{l}\text { De todo el material obtenido } \\
\text { en la primera fase de la inves- } \\
\text { tigación. }\end{array}$ & \\
\hline & $\begin{array}{l}\text { Triangulación y } \\
\text { categorización. }\end{array}$ & $\begin{array}{l}\text { Elaboración de cinco matrices } \\
\text { para focalizar los temas emer- } \\
\text { gentes y estructurar las catego- } \\
\text { rías de análisis. }\end{array}$ & $\begin{array}{l}\text { Mat1_DC } \\
\text { Mat2_EduM1 } \\
\text { Mat3_EduN2 } \\
\text { Mat4_EduS3 } \\
\text { Mat5_GD }\end{array}$ \\
\hline & $\begin{array}{l}\text { Interpretación } \\
\text { de los resulta- } \\
\text { dos. }\end{array}$ & $\begin{array}{l}\text { Profundización de las catego- } \\
\text { rías y posterior devolución de } \\
\text { los resultados a la entidad. }\end{array}$ & $\begin{array}{l}\text { VCE: Valoración del } \\
\text { coro por las educa- } \\
\text { doras. } \\
\text { VMM: Valoración } \\
\text { de la música por las } \\
\text { mujeres. } \\
\text { BCM: Beneficios del } \\
\text { coro en las mujeres. }\end{array}$ \\
\hline
\end{tabular}




\section{Discusión de resultados}

En el siguiente apartado mostramos cómo la música ha incidido positivamente en los procesos de inclusión de las usuarias que participan en el Coro Dona Góspel. A continuación presentamos la tabla de categorías y subcategorías que han sido elaboradas a partir del análisis cualitativo de datos.

Tabla 2: Categorías y subcategorías de análisis de datos. Elaboración propia

\begin{tabular}{|c|c|}
\hline Categorías & Subcategorías \\
\hline \multirow{3}{*}{$\begin{array}{l}\text { Valoración del Coro } \\
\text { Dona Góspel por las } \\
\text { educadoras }\end{array}$} & Poder transformador de la música \\
\hline & Arraigo del coro en la cultura del centro \\
\hline & Implementación pedagógica \\
\hline \multirow{3}{*}{$\begin{array}{l}\text { Valoración de la músi- } \\
\text { ca por las mujeres }\end{array}$} & La música para el bienestar individual \\
\hline & La música como espacio de participación comunitaria \\
\hline & Función simbólica de la música \\
\hline \multirow{4}{*}{$\begin{array}{l}\text { Beneficios del Coro } \\
\text { Dona Góspel en las } \\
\text { mujeres. }\end{array}$} & Ámbito normativo \\
\hline & Ámbito del bienestar personal \\
\hline & Ámbito de los vínculos sociales \\
\hline & Instancias de reconocimiento \\
\hline
\end{tabular}

\section{Valoración del Coro Dona Góspel por las educadoras}

El estudio realizado permitió detectar que, desde la perspectiva de las profesionales, la música dotaba de sentido a las personas marginadas. Ellas denominan a este elemento como el "poder transformador de la música”, porque, a pesar de que las mujeres en prostitución atraviesan un contexto vital complejo, cuando cantan se llenan de energía, mejoran su actitud, se visten adecuadamente para los conciertos, realizan su interpretación vocal con una entrega total y disfrutan al ver que el público recibe positivamente su arte. Tal y como menciona la Edu3: "el último concierto tú no habías dormido, estabas agotada, pero antes de entrar, tú ya cambiaste la cara y te pusiste maquillaje, voy aquí a dar lo mejor de mí misma” (GD_Muj1: 147). Quizás, la música ha permitido que las mujeres dejen de ser usuarias que constantemente reciben ayuda, dando paso a un rol que las empodera 
desde su papel como artistas. Reconocer sus talentos y saberes "implica dejar de tratar a las personas como sujetos receptores de asistencia y considerarlos capaces de ser ellos mismos los que aporten y den algo a la comunidad y a los demás" (Martín, Puig Gijón, 2018, p. 50).

A su vez, el coro ha adquirido un espacio importante dentro de la entidad. El equipo directivo, profesionales y voluntarias participaron regularmente en los ensayos y conciertos del coro, tal como menciona Edu_M1: "todo el Lloc se lo siente como algo suyo, o sea, el hecho mismo de que estemos ensayando, de que todas lo oyen, que se saben las canciones (...) lo sienten como algo propio" (Edu_M1: 95). Esto nos ha permitido constatar que existe un arraigo del coro en la cultura del centro, porque "a través de construir juntos, de reconocerse en los valores y principios de convivencia que contempla su particular mirada, la persona siente desde una conciencia personal y autónoma que forma parte de un proceso de construcción colectivo" (Cabrera, Donoso, Folgueiras y Luna, 2009, p. 65). Por tanto, la presencia del equipo directivo y profesional de la entidad ha sido importante para que las usuarias se sientan valoradas y comprometidas a participar.

Finalmente, creemos que esta categoría se ha producido porque las educadoras han dinamizado al coro con diversas implementaciones pedagógicas. Hemos visto cómo las profesionales han creado espacios de apertura a la comunidad, realizando meriendas, adquiriendo instrumentos musicales, participando en actividades culturales y reuniéndose con otros coros de Barcelona. Esto nos hace pensar que el taller de coro requiere de mucha dedicación y de una pedagogía que invite a pensar en mejoras e innovaciones para la agrupación, de manera que las mujeres se sientan motivadas a formar parte.

\section{Valoración de la música por las mujeres}

Según el análisis de datos, las mujeres mencionaron que realizar actividades musicales les ha provocado una sensación de bienes- 
tar individual. Detectamos que, cuando cantan, las mujeres olvidan sus tensiones, se sienten más relajadas, sonríen con mayor frecuencia e incluso olvidan por un momento las necesidades básicas y vitales que las aquejan. Tal como menciona la Muj1: "una vez que pongo música o canto (...) me pongo feliz, soy más fuerte, cuando no sabes cómo soltar alguna cosa o todo es demasiado pesado en tu cabeza solo utiliza música, canta y tráete a ti misma de vuelta" (GD_Muj: 139). Lo mencionado nos invita a pensar que "la música tiene una función catalizadora de la sensibilidad colectiva; a veces usada como válvula de escape, y otras como creación y clímax donde confluyen las emociones" (Vázquez, Fe y Guasch, 2012, p. 3). Por tanto, es un aliciente para enfrentar, de manera positiva, la realidad compleja que atraviesan las mujeres en contextos de exclusión.

Al mismo tiempo, hemos visto que la música ha estado presente en diversos espacios de participación comunitaria. Como menciona la educadora Edu_M1, "han cantado desde que tienen cuatro años (...) en la iglesia, con su familia, en su casa y lo tienen como muy naturalizado" (Edu_M1: 96). En este contexto la música es un elemento de identificación cultural, porque "goza de un papel privilegiado de transmisora de información y de acontecimientos relevantes de las diferentes comunidades" (Bernabé, 2015, p. 17). Esto ha sido fundamental para el desempeño de las mujeres como coristas, porque cantan con absoluta naturalidad en su vida cotidiana lo que les permite cantar con una actitud distendida cuando se presentan en público.

Finalmente, se detectó que la música posee una cualidad religiosa que permite a las mujeres trascender de su realidad. A esto llamaremos la "función simbólica de la música". Hemos develado que, cuando cantan, las mujeres se sienten más tranquilas, tienen una actitud reflexiva e incluso cierran sus ojos y abren sus brazos con una intencionalidad que invita a la plegaria. Tal como relata la Muj2, "no es solo una canción, es una proclamación hacia nuestro Dios" (GD_Muj:128). Al parecer, el medio musical les ha permitido llevar su alma a un viaje metafísico (Silver, 2017). Creemos 
que, si las entidades sociales incorporan esta función en sus proyectos de intervención, las personas reducirían su ansiedad, sentirían un enriquecimiento espiritual al cantar y, por tanto, habría un mayor compromiso en su participación.

\section{Beneficios del Coro Dona Góspel en las mujeres}

La triangulación de los datos obtenidos nos permitió sostener que los beneficios se dieron en tres aspectos. El primero corresponde al ámbito normativo, el segundo a su bienestar individual y el tercero a los espacios de reconocimiento.

En relación con el ámbito normativo, detectamos que las mujeres fueron incorporando las normas y hábitos de la comunidad de acogida mediante su participación en el coro. Recordemos que muchas de las mujeres en prostitución no duermen las horas que corresponden, no tienen una vivienda fija, no cuentan con dinero para transporte y les es muy difícil compaginar su actividad laboral con un itinerario formativo. Esto había sido una dificultad para las educadoras; tal como menciona la Edu_M1, "están en otros procesos vitales y que cuando tú les estas pidiendo, les estás pidiendo mucho" (Edu_M1: 101). Sin embargo, el Coro Dona Góspel -siendo una actividad extraordinaria- les permitió establecer una rutina, normas y hábitos necesarios para sentirse seguras y crear un sentido de pertenencia a la agrupación y a la entidad. Actualmente, las educadoras han visto que las mujeres son más independientes, asisten puntualmente a ensayos y conciertos, y han mejorado los canales de comunicación con sus compañeras y educadoras si no pueden presentarse a alguna actividad.

Por otra parte, es importante mencionar que muchas de las mujeres en estos contextos presentan un deterioro físico y emocional difícil de resolver. Han atravesado un trayecto migratorio complejo, están solas en el país de acogida, tienen que sostener económicamente a su familia, e incluso alguna viven relaciones de pareja complicadas. A pesar de ello, participar en el co- 
ro les ha permitido divertirse, compartir con sus compañeras y hablar de lo cotidiano sin sentirse juzgadas o supervisadas. Por este motivo, creemos que el coro ha incidido directamente en su bienestar personal, porque "así como el crecimiento individual amplía el espectro relacional y permite una mayor empatía, confianza y capacidad de respuesta interpersonal, las relaciones positivas contribuyen al desarrollo personal y construyen la autoestima" (Silber, 2007, p. 264). Tal como hemos visto en ensayos y conciertos, las mujeres bailan, cantan, cierran sus ojos, sonríen, realizan chasquidos con sus dedos y trinan sus labios para demostrar su felicidad. Quizás, a nivel pedagógico, las actividades artísticas que se generan en espacios de distención colectiva permiten que las mujeres se sientan optimistas y felices consigo mismas a pesar de su realidad.

A su vez, mediante su participación en el coro, las mujeres han tenido la oportunidad de construir vínculos sociales con sus compañeras, educadoras y voluntarias del centro, y con la comunidad de acogida. En relación a sus compañeras, educadoras y voluntarias, el coro les ha brindado instancias para compartir experiencias, expectativas, proyectos vitales, saberes y talentos de cada una, estrechando lazos significativos de amistad. Respecto de los vínculos con la comunidad, podemos decir que, mediante los conciertos realizados, las mujeres han conocido lugares emblemáticos de Barcelona, las personas del público se acercan, las felicitan y en reiteradas ocasiones las han invitado a participar de otras actividades culturales. Este "es un dinamismo que permite reestablecer la confianza y reparar el daño que la exclusión ha dejado en la identidad, y que, además, logra reconstruir relaciones y optimizar la estima social de la comunidad" (Martinez, Puig y Gijón, 2018, p. 49). Tengamos en cuenta que las mujeres en prostitución generalmente trabajan cerca de su lugar de residencia y, por tanto, no han cimentado redes de ayuda alejadas de esos circuitos. Creemos que implementar proyectos sociales que tengan espacios de vinculación con la comunidad, permite que las personas vulnerables reconstruyan sus redes de ayuda mutua y desarrollen un grado de 
independencia respecto de los espacios que podrían incrementar la guetificación.

Finalmente, es importante recordar que las participantes de este estudio sufren el estigma de la prostitución como una huella que ha marcado su vida en múltiples aspectos. Por este motivo, consideramos que los beneficios causados por el coro en relación con el reconocimiento han sido fundamentales para la reconstrucción individual y social de las mujeres. A continuación, mostramos de qué manera las instancias de reconocimiento se han presentado en diferentes niveles. El primero se relaciona con las mujeres como compañeras de coro, el segundo con las educadoras y voluntarias del centro y, el tercero, con la comunidad de acogida. Respecto de las mujeres como compañeras, hemos visto que durante los ensayos respetan las intervenciones de cada una para escuchar sus propuestas de repertorio y/o se refuerzan positivamente cuando realizan una interpretación vocal correcta. Esto indica que las mujeres se reconocen entre ellas como interlocutoras válidas dentro de una comunidad coral, aprecian sus talentos y potencian mutuamente los aprendizajes vinculados a la música. Asimismo, debido al talento y experiencia que han demostrado en relación con esta disciplina, las educadoras les han entregado un rol protagónico. Tal y como menciona la Edu2_N: "madre mía, estas mujeres me tienen que enseñar a mí, no yo a ellas” (Edu_N2: 117). Esto ha permitido que el coro se transforme en un espacio de participación igualitaria, donde las mujeres han ganado seguridad, mejorado su interpretación vocal y adquirido el protagonismo en la toma de decisiones respecto de las actividades corales. A su vez, la comunidad ha valorado su calidad vocal y ha recibido su diversidad cultural de manera positiva en espacios de goce artístico. Tal como relata la Muj2, "nosotras somos diferentes, tenemos otro color, somos de otra ciudad, cantándoles” (GD_Muj1: 129). Esto ha permitido que se sientan orgullosas de sus particularidades, dejen de lado el estigma de la prostitución y sean reconocidas como artistas en espacios de deleite cultural. 


\section{Conclusiones}

Hemos constatado que el Coro Dona Góspel ha brindado soluciones a aquellas necesidades de orden vital que presentan las mujeres en prostitución, por tanto, les ha permitido reforzar sus hábitos y normas, fortalecer su autoestima y sensación de bienestar, favorecer la estructuración de vínculos sociales y promover instancias de reconocimiento en un entorno seguro y de placer musical.

Asimismo, hemos observado que las mujeres han ganado en experiencia y autonomía, puesto que algunas de sus integrantes han realizado eventos musicales de manera independiente en diversos centros culturales de Barcelona, recibiendo una remuneración por su desempeño como artistas. Creemos que esto significa un paso fundamental para su emancipación, entendiendo que desempeñar esta disciplina como un trabajo puede ofrecer respuestas tangibles a aquellas necesidades básicas que aquejan a las mujeres en prostitución.

También consideramos que un proyecto social de estas características necesita dedicación, supervisión, planificación, coordinación entre entidades e implementación de mejoras para su continuidad. Sumado a ello, las relaciones de cuidado y acompañamiento que se dan entre educadoras y mujeres $-y$ con esto nos referimos al "tacto pedagógico" - son fundamentales en el proceso. Por este motivo, es necesario enfatizar que llevar a cabo el Coro Dona Góspel implica un compromiso reflexivo por "hacer" pedagogía, ya que el proyecto no puede sostenerse solo y necesita de la acción permanente por parte de las profesionales y del equipo directivo para su dinamización y progreso.

Por otra parte, uno de los resultados que no hemos sistematizado a nivel de categorías pero que se detectó al finalizar el estudio, ha sido el beneficio del coro en las mujeres cuando adquieren un rol de responsabilidad ciudadana. Esto se ha podido ver porque el último trimestre del presente año el Coro Dona Góspel se 
reunió con un coro de adolescentes pertenecientes al CRAE ${ }^{6}$, de Cerdanyola del Vallès, con la voluntad de compartir y ensayar el repertorio musical de ambos. Finalmente, los coros realizaron un concierto en el Auditori de Barcelona. Esta experiencia permitió que las mujeres adquirieran un rol de educadoras con otras jóvenes $y$, de ser usuarias de la entidad, pasaron a ser artistas ejemplares para las jóvenes del CRAE. Creemos que este suceso configura el inicio de una fase superior en el Coro Dona Góspel, vinculada a la línea del Don y Reconocimiento como una nueva mirada de la intervención social, en la que "se pretende ayudar a las personas a reparar la huella de la exclusión y a reconstruir sus proyectos vitales poniendo en valor sus aprendizajes, saberes y experiencias, y creando las condiciones para que puedan activarlos en situaciones de altruismo" (Martín, Puig \& Gijón, 2018, p. 49).

Finalmente, consideramos que llevar a cabo un proceso de investigación riguroso ha sido un catalizador para que educadoras y mujeres tomen conciencia de los beneficios que trae el desarrollo de una actividad musical en este colectivo. Mediante espacios de reflexión continua, las implicadas develaron que el Coro Dona Góspel sí era una instancia de participación ciudadana que promueve la autonomía, favorece la identificación cultural, potencia el desarrollo de sus talentos y brinda espacios de reconocimiento y de vinculación con la comunidad. Por ello, es tan importante implementar acciones pedagógicas que mantengan activo al taller de canto, ya que, sin duda, la música ha sido una herramienta de inclusión para las mujeres del Coro Dona Góspel.

La sigla CRAE corresponde a Centro Residencial de Acción Educativa, también conocido como centro de menores tutelados de protección a la infancia. Es una institución dependiente de la Generalitat, localizada en la Comunidad Autónoma de Catalunya. Tiene como objetivo acoger a cualquier menor para brindar un recurso alternativo al entorno familiar inexistente, deteriorado o con graves dificultades para cubrir sus necesidades básicas. 
Coro Dona Góspel: un camino musical hacia lo mejor de sí mismas. Diagnóstico participativo en el colectivo de mujeres en prostitución /Espinoza.

\section{Bibliografía}

Bernabé, M. (2015). Organización intercultural en el aula de música de Secundaria. Revista Electrónica Interuniversitaria de Formación del Profesorado, 18(3), 13-24.

Cabrera, F., Donoso, T., Folgueiras, P. y Luna, E. (2009). La participación ciudadana: un reto para la educación para la ciudadanía. La Salle-Revista de Educaçao, Ciencia e Cultura, 14 (1).

Cabrerizo, M. (2016). Situación Socio-sanitaria de mujeres que ejercen la prostitución en Almería (tesis de doctorado). , España Recuperado de http://digibug.ugr.es/handle/10481/40940

Congreso de los Diputados. (2007). Boletín Oficial de las Cortes Generales, Vol. A (379). Madrid. Recuperado de http://www.congreso.es/public_oficiales/L8/CORT/BOCG/A/CG_A379. PDF

Díaz de Rada y Velasco H. (1997). La lógica de la investigación etnográfica. Un modelo de trabajo para etnógrafos de la escuela. Madrid: Ed. Trotta.

El Lloc de la Dona. (2016). Memoria 2016. Construyendo futuro. Barcelona: El Lloc de la Dona. Recuperado de http://www.llocdeladona.org/es/memories/

Equipo del Observatorio del Tercer Sector de Bizkaia. (2012). Arte para la inclusión y la transformación social. Euskadi, España: . Recuperado de http://www.3sbizkaia.org/Archivos/Documentos/Enlaces/1363_CAST-innovacion04.pdf

Folgueiras, P. y Sabariego, M. (2017). Investigación-acción participativa. El diseño de un diagnóstico participativo. REIRE. Revista D'Innovació i Recerca En Educació, 16-25. Recuperado de revistes.ub.edu/index.php/REIRE/article/download/reire2018.11.119047/21933

Gijón, M. (2012). Micropedagogías y alquimias de la relación: saberes de mujeres en contextos de prostitución, en R. L. M. Belausteguigoitia (Ed.), Pedagogías en Espiral. Experiencias $y$ prácticas. (pp. 217-245). México: Universidad Nacional Autónoma de México.

Heim, D. (2011). Prostitución y Derechos Humanos. Cuadernos Electrónicos de Filosofía Del Derecho, 23, 234-252. Recuperado de https://ojs.uv.es/index.php/CEFD/article/view/716/472

Holgado, I. (2001). Las nuevas retóricas de la inmigración femenina: la prostitución en las calles de Barcelona. Scripta Nova. Revista Electrónica de Geografía y Ciencias Sociales (94), 100. Recuperado de http://www.ub.edu/geocrit/sn-94100.htm 
Juliano, D. (2009). Delito y pecado. La transgresión en femenino. Política y Sociedad, 46(1-2), 79-95. Recuperado de http:// revistas.ucm.es/index.php/POSO/article/view/POSO0909130079A

Martín, X., Puig, J. \& Gijón, M. (2018). Reconocimiento y don en la educación social. EDETANIA, 53, 45-60. Recuperado de revistas.ucv.es/index.php/Edetania/article/download/336/359/

Ministerio de Sanidad y Servicios Sociales de España. (2015). El sistema público de servicios sociales. Recuperado de https://www. mscbs.gob.es/ssi/familiasInfancia/ServiciosSociales/docs/ InformeRMI2015.pdf

Ordoñez, A. (2006). Feminismo y prostitución: Fundamentos del debate actual en España. España: Asociación Feminista de Asturias.

PNUD. (2014). Informe sobre desarrollo humano 2014. Recuperado de https://www.undp.org/content/dam/undp/library/corporate/HDR/2014HDR/HDR-2014-Spanish.pdf

Sabariego, M. (2009). La investigación educativa: Génesis, Evolución, y Características, in R. Bisquerra (Ed.), Metodología de la Investigación Educativa (pp. 65-87). Madrid: La Muralla.

Sampietro, L. (2015). Inclusión Social a través de la Música. Entrevista a Beatriz Pedro-Viejo. Revista-Red de Estudios Sociales Iberoamérica Social, 1-7. Recuperado de https://iberoamericasocial.com/inclusion-social-a-traves-de-la-musicaentrevista-a-beatriz-pedro-viejo-perez-gestora-culturalcon-enfoque-social-y-musico-profesional-promotora-dela-plataforma-redomi-y-del-programa-musicosocial/

Sandín, M. (2003). Investigación cualitativa en educación: fundamentos y tradiciones. Madrid: McGrawHill.

Sassen, S. (2003). Contrageografías de la globalización. Género y ciudadanía en los circuitos transfronterizos. Madrid: Traficantes de Sueños.

Silber, L. (2005). Bars behind bars: the impact of a women's prison choir on social harmony. Music Education Research, 7(2), 251271.

Urrutia, E. (2015). Discurso de saludo de aniversario número 69. Liceo Artístico Guillermo Gronemeyer. Recuperado de www.liceoartisticoquilpue.com/documentos/discursoCCAA.pdf

Vázquez, D., Fe, R. y Guasch, N. (2012) Los ronderos: Melodías para la inclusión social. RES Revista de educación social, (14). 